\title{
Testosterone association with blood pressure profile and left ventricular mass in a young hypertensive population
}

\author{
Marta Sołtysiak, Jacek Głowala, Joanna Ziemak, Paweł Sołtysiak, Tomasz Miazgowski, \\ Krystyna Widecka
}

Klinika Hipertensjologii i Chorób Wewnętrznych Pomorskiego Uniwersytetu Medycznego

\begin{abstract}
Sex hormones not only regulate the gonads function, but also may affect the cardiovascular system, although their role is still not clear. Testosterone influence on arterial pressure and left ventricular hypertrophy were widely reported. A number of factors have been implicated as the underlying cause of the relation between testosterone and blood pressure, including sex and age as most important ones. In present findings, a 24-hour ABPM revealed that $33.9 \%$ of patients had an altered pattern of blood pressure with no significant differences between sexes. In the whole studied sample, positive correlation has been found between testosterone and 24-hour systolic blood pressure, daytime BP, sodium and potassium levels in the 24-hour urine collection, and left ventricular mass index. In conclusion, testosterone association with blood pressure profile and left ventricular mass in a young hypertensive population seems to be probable, but further analysis is necessary.
\end{abstract}

Key words: testosterone, blood pressure

Arterial Hypertens. 2016, vol. 20, no. 4, pages: 200-205 DOI: $10.5603 / A H .2016 .0022$

\section{Introduction}

Sex hormones not only regulate the gonads' function but also may affect the cardiovascular system, although their role is still not clear [1-5].

Referring to the testosterone influence on arterial pressure, literature has known many mechanisms of which androgen-dependent gender differences were widely reported [3, 6]. Similarly, the relationship between testosterone levels and an unfavourable BP response for testosterone chronic supplementation driven by activation of renin-angiotensin system (RAS) $[7,8]$.

Since declining gonadal function with aging is known, age need be taken into account to examine the relationship between testosterone and blood pres- sure $[9,10]$. The results of previous studies performed in elderly and middle-aged patients indicate the association between testosterone levels and hypertension $[1,3,9,11]$. Data in the young population are inadequate. The aim of this study was to explore the relationship between testosterone and blood pressure profile in young hypertensive patients.

\section{Materials and methods}

\section{Study population}

The study was carried out among patients with established diagnosis of essential hypertension treated at university-affiliated Department of Hypertension

Address for correspondence: Marta Soltysiak, MD

Department of Hypertension and Internal Diseases, Pomeranian Medical University ul. Unii Lubelskiej 1, 71-252 Szczecin, tel. (091) 425-35-50; fax: (091) 425-35-52 e-mail: marta.soltysiak00@gmail.com

VM Copyright (C 2016 Via Medica, ISSN 2449-6170 
and Internal Medicine in Szczecin. Overall, we included 80 consecutive hypertensive patients $(35 \mathrm{fe}-$ males, 45 males), mean age $29.9 \pm 16.3$ years. We excluded those patients who were treated with spironolactone, glucocorticoids, anabolic steroids, and oral contraception. We also evaluated 24-hour urinary potassium (normal range: $25-125 \mathrm{mmol} / 24 \mathrm{~h}$ ) and sodium (normal range: $40-220 \mathrm{mmol} / 24 \mathrm{~h}$ ) excretion. Based on medical history and medical records, we collected data on family cardiovascular burden, smoking habits, dyslipidaemia, chronic kidney disease, and type 2 diabetes.

\section{Measurements}

Anthropometric measurements were taken and body mass index (BMI) was calculated from the body weight and height. In all cases, we performed 24hour blood pressure monitoring (ABPM) (Spacelabs Healthcare) and analysed 24-hour daytime and nocturnal systolic, diastolic, and mean blood pressure. Testosterone (normal range for men: 4.25-30.37 $\mathrm{pg} / \mathrm{ml}$; normal range for women: $0.04-4.18 \mathrm{pg} /$ $\mathrm{ml}$ ), PRA (normal range: $0.51-2.64 \mathrm{ng} / \mathrm{ml} / \mathrm{h}$ ) and plasma aldosterone (normal range: $10-160 \mathrm{pg} / \mathrm{ml}$ ) were measured using commercially available assays. From these measurements we calculated the aldosterone-to-renin ratio (ARR). In reference to the current guidelines, the left ventricular mass index has been assessed in all cases [12]. Echocardiography was performed by using a GE Vivid S6 device [12].

\section{Statistical analysis}

Descriptive data are presented as mean \pm SD or numbers and percentage. When comparing normally distributed variables between groups of men and women, an independent $t$ test was used for comparing means. For comparison of skewedly distributed variables between the study groups, median values were calculated and Mann-Whitney $\mathrm{U}$ and/ or Kruskal-Wallis test was used. Categorical variables were evaluated by Chi square test. Correlations between the study variables were evaluated by Spearman's rank correlation. $\mathrm{P}$ values $<0.05$ were considered significant. All analyses were carried out in Statistica version 12 (Statsoft, Poland).

\section{Results}

The main clinical and biochemical characteristics of the study sample are shown in Tables I-IV. Majority of subjects were overweight/obese. As many as $82.5 \%$ of patients had a positive family history of cardiovascular disease. Additionally, $42.3 \%$ were
Table I. Baseline clinical characteristics of the study population ( $\mathrm{n}=80$ )

\begin{tabular}{|l|c|}
\hline & $\begin{array}{c}\text { Mean value ( } \pm \text { SD) } \\
\text { Median (range) }\end{array}$ \\
\hline Age (years) & $29.9 \pm 16.3$ \\
& $30(19.0-43.0)$ \\
\hline BMl $[\mathrm{kg} / \mathrm{m} 2]$ & $28.6 \pm 6.2$ \\
& $27.5(19.4-48.0)$ \\
\hline Duration of hypertension (months) & $45.6 \pm 57.3$ \\
& $24.0(1.0-308.0)$ \\
\hline SBP $[\mathrm{mm} \mathrm{Hg}]$ & $148.3 \pm 16.3$ \\
& $148(114.0-190.0)$ \\
\hline DBP $[\mathrm{mm} \mathrm{Hg}]$ & $109.9 \pm 12.4$ \\
& $90(62.0-130.0)$ \\
\hline MAP $[\mathrm{mm} \mathrm{Hg}]$ & $109.9 \pm 12.0$ \\
& $109.5(83.3-146.7)$ \\
\hline Women & $\%(\mathrm{n})$ \\
\hline Men & $43.7 \%(35)$ \\
\hline Smokers & $56.3 \%(45)$ \\
\hline Family CVD history & $42.3 \%(44)$ \\
\hline BMl $<25 \mathrm{~kg} / \mathrm{m} 2$ & $82.5 \%(66)$ \\
\hline BMl $\geq 25<30 \mathrm{~kg} / \mathrm{m} 2$ & $27.5 \%(22)$ \\
\hline BMl $\geq 30 \mathrm{~kg} / \mathrm{m} 2$ & $41.3 \%(33)$ \\
\hline SD & $31.2 \%(25)$ \\
\hline
\end{tabular}

SD — standard deviation; BMI — body mass index; SBP — systolic blood pressure; DBP — diastolic blood pressure; MAP — mean arterial pressure

Table II. Selected echocardiographic parameters of the study population $(\mathrm{n}=80)$

\begin{tabular}{|l|c|}
\hline & $\begin{array}{c}\text { Mean ( } \pm \text { SD) } \\
\text { Median (range) }\end{array}$ \\
\hline LVMI [g/m2] & $81.3 \pm 19.5$ \\
& $79.2(18.7-136.7)$ \\
\hline RWT & $0.5 \pm 1.9$ \\
& $0.3(0.2-17.2)$ \\
\hline Septal velocity [cm/s] & $12.3 \pm 3.1$ \\
& $12.0(5.3-20.0)$ \\
\hline Lateral velocity [cm/s] & $15.6 \pm 3.4$ \\
& $15.3(8.0-25.0)$ \\
\hline LAVI [ml/m2] & $18.6 \pm 9.1$ \\
& $17.1(2.4-87.4)$ \\
\hline E/e' Ratio & $5.9 \pm 2.2$ \\
& $5.7(1.2-19.9)$ \\
\hline
\end{tabular}

smokers. A 24-hour ABPM revealed that 33.9\% of patients had an altered pattern of blood pressure (non-dipping, reverse-dipping, or extreme-dipping) with no significant differences between sexes. In the whole studied sample, positive correlation has been 
Table III. Biochemical and hormonal characteristics of study population $(\mathrm{n}=80)$

\begin{tabular}{|l|c|}
\hline & $\begin{array}{c}\text { Mean ( } \pm \text { SD) } \\
\text { Median (range) }\end{array}$ \\
\hline Serum sodium level [mmol/]] & $141.0 \pm 1.8$ \\
& $141.0(136.0-145.0)$ \\
\hline Serum potassium level [mmol/] & $4.4 \pm 0.3$ \\
& $4.4(3.7-5.1)$ \\
\hline Sodium in 24h urine collection & $183.7 \pm 62.5$ \\
[mmol/24h] & $175.2(73.0-361)$ \\
\hline Potassium in 24h urine collection & $54.0 \pm 20.2$ \\
[mmol/24h] & $50.7(17.0-141.0)$ \\
\hline PRA [ng/ml/h] & $1.5 \pm 0.6$ \\
& $1.5(0.6-3.2)$ \\
\hline Aldosterone [pg/ml] & $105.7 \pm 36.5$ \\
& $108.0(31.0-178.0)$ \\
\hline ARR & $7.1 \pm 2.7$ \\
& $7.0(1.4-17.2)$ \\
\hline Testosterone [pg/ml] & $10.4 \pm 11.4$ \\
& $7.5(0.6-70.2)$ \\
\hline
\end{tabular}

PRA — plasma renin activity; ARR — aldosterone/renin ratio

found between testosterone and 24-hour systolic blood pressure, daytime BP, sodium and potassium levels in the 24-hour urine collection, and left ventricular mass index (Table V). There was only weak negative correlation between total testosterone (TT) and nocturnal diastolic blood pressure $(\mathrm{p} \leq 0.02)$. Compared with female, men had significantly higher testosterone level, 24-hour and daytime systolic blood pressure and lower nocturnal diastolic blood pressure (Table VI). Testosterone level was inversely correlated with age. We did not found significant association between TT and non- dipping profile after adjusting for age.

\section{Discussion}

In the past decades, the associations between egzoand endogenous testosterone (TT) and blood pressure (BP) in males and females have been extensively studied; however, inconsistent results have been obtained. In the present findings a 24-hour ABPM revealed that $33.9 \%$ of patients had an altered pattern of blood pressure (non-dipping, reverse-dipping, or extreme-dipping) with no significant differences between sexes. A positive correlation has been found between testosterone and 24-hour systolic blood pressure, daytime BP. This findings are in line with the general research trend $[1,11,13,14]$. Literature suggests various mechanisms involved in the testosterone impact on blood pressure regulation.
Table IV. 24-hour ambulatory blood pressure monitoring parameters in study population $(\mathrm{n}=80)$

\begin{tabular}{|l|c|}
\hline & $\begin{array}{c}\text { Mean } \pm \text { SD } \\
\text { Median (range) }\end{array}$ \\
\hline 24 SBP [mm Hg] & $126.2 \pm 10.5$ \\
& $126.5(102.0-177.0)$ \\
\hline 24 DBP [mm Hg] & $75.9 \pm 8.3$ \\
& $75.5(53.0-109.0)$ \\
\hline 24 MAP [mm Hg] & $92.2 \pm 8.1$ \\
\hline SBPd [mm Hg] & $91.0(76.0-132.0)$ \\
\hline DBPd [mm Hg] & $132.5 \pm 12.1$ \\
\hline MAPd [mm Hg] & $129.0(105.0-181.0)$ \\
\hline SBPn [mm Hg] & $78.7 \pm 8.4$ \\
& $79.0(54.0-111.0)$ \\
\hline DBPn [mm Hg] & $94.4 \pm 12.8$ \\
& $94.0(46.0-144.0)$ \\
\hline MAPn [mm Hg] & $114.9 \pm 12.8$ \\
& $116.0(80.0-140.0)$ \\
\hline Dippers & $68.6 \pm 10.5$ \\
\hline Non-dippers & $67.0(51.0-125.0)$ \\
\hline Reverse-dippers & $83.0 \pm 11.5$ \\
\hline Extreme-dippers & $84.0(42.0-121.0)$ \\
\hline & $\%(\mathbf{n})$ \\
\hline & $66.1 \%(53)$ \\
\hline & $31.3(25)$ \\
\hline & $1.3 \%(1)$ \\
\hline & $1.3 \%(1)$ \\
\hline & 9400 \\
\hline
\end{tabular}

24 SBP - 24-hour systolic blood pressure; $24 \mathrm{DBP}$ - 24-hour diastolic blood pressure; $24 \mathrm{MAP}-$ 24-hour mean arterial pressure; SBPd — daytime systolic blood pressure; DBPd — daytime diastolic blood pressure; MAPd — daytime mean arterial pressure; $\mathrm{SBPn}$ — nocturnal systolic blood pressure; $\mathrm{DBPn}$ - nocturnal diastolic blood pressure; $\mathrm{MAPn}$ - nocturnal mean arterial pressure

In animal models, chronic testosterone supplements caused hypertension in male spontaneously hypertensive rats (SHR) and this unfavourable $\mathrm{BP}$ response was mainly driven by activation of renin-angiotensin system (RAS) [7]. In addition, prenatal testosterone exposure in female rats resulted in increased serum vasopressin and angiotensin II concentrations, leading to the development of hypertension [8], while a chronic blockade of RAS with enalapril abolished age-dependent changes in BP [15], suggesting that the RAS promotes oxidative stress leading to production of vasoconstrictor substances and reduction in nitric oxide availability. In our study, we have not observed any relationship between TT and RAS, but it may be due to small sample size.

Salt-sensitivity of blood pressure has been suggested as a result of the interaction of many genetic and environmental factors [16]. In recent years testosterone-dependent pressure-natriuresis relationship has been highlighted $[3,6,17,18]$. According to these data, we have shown a positive correlation 
Table V. Correlations between testosterone serum level and selected parameters

\begin{tabular}{|c|c|c|c|}
\hline & Variables & $\mathbf{R}$ & P-value \\
\hline \multirow{23}{*}{$\begin{array}{l}\text { Testosterone } \\
{[\mathrm{pg} / \mathrm{ml}]}\end{array}$} & Age (years) & -0.25 & $p<0.03$ \\
\hline & BMI $\left[\mathrm{kg} / \mathrm{m}^{2}\right]$ & -0.05 & ns \\
\hline & Duration of hypertension (months) & 0.16 & ns \\
\hline & $24 \mathrm{SBP}[\mathrm{mm} \mathrm{Hg}]$ & 0.22 & $p<0.05$ \\
\hline & $24 \mathrm{DBP}[\mathrm{mm} \mathrm{Hg}]$ & -0.20 & ns \\
\hline & $24 \mathrm{MAP}[\mathrm{mm} \mathrm{Hg}$ & -0.01 & ns \\
\hline & SBPd $[\mathrm{mm} \mathrm{Hg}]$ & 0.23 & $\mathrm{p}<0.04$ \\
\hline & $\mathrm{DBPd}[\mathrm{mm} \mathrm{Hg}]$ & -0.01 & ns \\
\hline & MAPd [mm Hg] & -0.16 & ns \\
\hline & SBPn [mm Hg] & 0.04 & ns \\
\hline & $\mathrm{DBPn}[\mathrm{mm} \mathrm{Hg}]$ & -0.28 & $\mathrm{p}<0.02$ \\
\hline & MAPn [mm Hg] & -0.16 & ns \\
\hline & Sodium in $24 \mathrm{~h}$ urine collection $[\mathrm{mmol} / 24 \mathrm{~h}]$ & 0.26 & $p<0.03$ \\
\hline & Potassium in $24 \mathrm{~h}$ urine collection [mmol/24h] & 0.25 & $p<0.03$ \\
\hline & PRA [ng/ml/h] & -0.02 & ns \\
\hline & Aldosterone [pg/ml] & -0.06 & ns \\
\hline & ARR & -0.21 & ns \\
\hline & LVdMI $\left[\mathrm{g} / \mathrm{m}^{2}\right]$ & 0.26 & $p<0.03$ \\
\hline & RWT & 0.15 & ns \\
\hline & Septal velocity $[\mathrm{cm} / \mathrm{s}]$ & -0.14 & ns \\
\hline & Lateral velocity $[\mathrm{cm} / \mathrm{s}]$ & -0.06 & ns \\
\hline & LAVI $\left[\mathrm{ml} / \mathrm{m}^{2}\right]$ & -0.07 & ns \\
\hline & E/e' Ratio & 0.01 & ns \\
\hline
\end{tabular}

$\mathrm{R}-$ Spearman rank correlation coefficient; $\mathrm{ns}-\mathrm{no}$ statistical significance

Table VI. Comparison of selected parameters among women and men groups

\begin{tabular}{|l|c|c|c|}
\hline & $\begin{array}{c}\text { Women } \\
(\mathbf{n}=35)\end{array}$ & $\begin{array}{c}\text { Men } \\
(\mathbf{n}=45)\end{array}$ \\
\hline Age (years) & $30.3 \pm 7.3$ & $29.5 \pm 10.1$ & $\mathrm{~ns}$ \\
\hline BMl $\left[\mathrm{kg} / \mathrm{m}^{2}\right]$ & $28.3 \pm 6.0$ & $28.8 \pm 6.4$ & $\mathrm{~ns}$ \\
\hline Testosterone $[\mathrm{pg} / \mathrm{ml}]$ & $3.8 \pm 3.2$ & $15.5 \pm 10.1$ & $\mathrm{p}<0.0001$ \\
\hline 24 SBP $[\mathrm{mm} \mathrm{Hg}]$ & $122.7 \pm 9.9$ & $130.0 \pm 10.1$ & $\mathrm{p}<0.05$ \\
\hline 24 DBP $[\mathrm{mm} \mathrm{Hg}]$ & $77.1 \pm 8.5$ & $75.0 \pm 8.1$ & $\mathrm{~ns}$ \\
\hline 24 MAP $[\mathrm{mm} \mathrm{Hg}]$ & $91.9 \pm 8.5$ & $92.4 \pm 7.8$ & $\mathrm{~ns}$ \\
\hline SBPd $[\mathrm{mm} \mathrm{Hg}]$ & $127.4 \pm 13.1$ & $132.9 \pm 10.8$ & $\mathrm{p}<0.005$ \\
\hline DBPd $[\mathrm{mm} \mathrm{Hg}]$ & $79.9 \pm 8.0$ & $77.9 \pm 8.8$ & $\mathrm{~ns}$ \\
\hline MAPd $[\mathrm{mm} \mathrm{Hg}]$ & $94.9 \pm 15.3$ & $94.2 \pm 10.6$ & $\mathrm{~ns}$ \\
\hline SBPn $[\mathrm{mm} \mathrm{Hg}]$ & $114.8 \pm 12.1$ & $115.0 \pm 7.7$ & $\mathrm{~ns}$ \\
\hline DBPn $[\mathrm{mm} \mathrm{Hg}]$ & $71.9 \pm 13.3$ & $66.1 \pm 6.8$ & $\mathrm{p}<0.02$ \\
\hline MAPn $[\mathrm{mm} \mathrm{Hg}]$ & $83.6 \pm 13.4$ & $82.6 \pm 9.9$ & $\mathrm{~ns}$ \\
\hline Dippers & $54.3 \%(19)$ & $76.0 \%(34)$ & $\mathrm{ns}$ \\
\hline Non-dippers & $45.1(15)$ & $24.0 \%(11)$ & $\mathrm{ns}$ \\
\hline Reverse-dippers & $0.9 \%(1)$ & $0 \%(0)$ & $\mathrm{ns}$ \\
\hline
\end{tabular}

24 SBP — 24-hour systolic blood pressure; 24 DBP — 24-hour diastolic blood pressure; 24 MAP — 24-hour mean arterial pressure; SBPd — daytime systolic blood pressure; DBPd — daytime diastolic blood pressure; $\mathrm{MAPd}$ - daytime mean arterial pressure; $\mathrm{SBPn}$ — nocturnal systolic blood pressure; $\mathrm{DBPn}$ — nocturnal diastolic blood pressure; MAPn — nocturnal mean arterial pressure 
between TT and sodium excretion in 24-hour urine collection.

Some studies examining the relationship between TT and blood pressure suggest that BP increase is secondary to obesity and insulin resistance [19-21]. However, in contrast to these opinion, other studies demonstrated that independently of food intake and weight gain, hyperandrogenaemia did not exacerbate hypertension in female SHR [22]. Because the majority of our respondents were overweight/ obese, further studies are needed to assess this relationship.

A number of factors have been implicated as the underlying cause of the relation between testosterone and blood pressure, including sex and age as most important ones. Our findings showed that testosterone level was inversely correlated with age. Compared with female, men had significantly higher testosterone level, 24-hour and daytime systolic blood pressure and lower nocturnal diastolic blood pressure. We did not found significant association between TT and altered BP profile after adjusting for age.

The influence of sex hormones on the cardiovascular system at least partially explains the occurrence of sex-dependent epidemiological differences in the incidence of hypertension among men and women. In early human studies performed in men, a stepwise decrease in mean systolic and diastolic BP per increasing quartile of testosterone was shown [14], suggesting a linear relationship between circulating hormone level and BP. However, in the recent study carried out in healthy men aged $20-50$ years, changes in BP did not appear to be regulated by testosterone levels [23]. Moreover, in hypogonadal elderly men, long-term testosterone therapy was associated with a significant decrease in systolic and diastolic BP [24]. As showed the findings from the NHANES III study, men generally have a higher pressure than women through middle age [25]. This difference is clear until women reach menopause and the lack of hypotensive effect of hormone replacement therapy indicates oestrogen-independent mechanism [26, 27]. Ziemens et al. in the longitudinal women-population-based study demonstrated a positive association between total testosterone and the incidence of hypertension [13]. It also has been suggested that free androgen index might be a robust biomarker of the transition to new onset hypertension and higher BP category in postmenopausal women [28]. The impact of testosterone on blood pressure seems to be confirmed by the fact that women with polycystic ovary syndrome or virilising tumours are frequently diagnosed with hypertension [29-31]. On the other hand, some studies showed no association between testosterone level and BP in peri- and postmenopausal period $[32,33]$.

In reference to the current guidelines, the assessment of organ damage, including left ventricular mass index, is important to stratify cardiovascular risk in patients with hypertension [12]. Since the relationship between anabolic steroids abuse and sudden cardiac death was observed, many studies have reported an association between testosterone and ventricular hypertrophy [34]. It has been proven that testosterone affect the cardiomyocytes proliferation and promotes cardiac hypertrophy [35]. Consistently, an inverse association between testosterone concentration and central systolic BP (major determinant of left ventricular hypertrophy [LVH]) was reported [36]. Being in line with the majority of reports [37], the current study showed a positive correlation between TT and left ventricular mass index. Opposite to this findings, Gyllenborg et al. has found no association between testosterone levels and LVH [38].

In conclusion, testosterone association with blood pressure profile and left ventricular mass in a young hypertensive population seems to be probable but further analysis is necessary.

\section{Acknowledgments}

The present study was partially financed by a Pomeranian Medical University grant for young scientists number MB 147-03/15.

\section{References}

1. Łącka K., Czyżyk A. Hormones and the cardiovascular system. Pol. J. Endorinol. 2008; 59: 120-432.

2. Brand J.S., van der Schouw Y.T. Testosterone, SHBG and cardiovascular health in postmenopausal women. Int. J. Imopt. Res. 2010; 22: 91-104.

3. Kienitz T., Quinkler M. Testosterone and blood pressure regulation. Kidney Blood Press. Res. 2008; 31: 71-79.

4. Torkler S., Wallaschofski H., Baumeister S.E. et al. Inverse association between total testosterone concentrations, incident hypertension and blood pressure. Aging Male 2011; 14: 176-182.

5. Gannage-Yared M.H., Chedid R., Abs L. Relation between androgens and cardiovascular risk factors in a young population. Clin. Endocrinol. (Oxf.) 2011; 74: 720-125.

6. Reckelhoff J.F. Gender differences in the regulation of blood pressure. Hypertension 2001; 37: 1199-1208.

7. Maranon R.O., Yanes Cardozo L.L., Dalmasso C. et al. Testosterone increases BP in male SHR by activating the renin-angiotensin system: a cautionary tale for "low T" supplements. Hypertension 2015; 66: AP039.

8. More A.S., Mishra J.S., Hankins G.D., Kumar S. Prenatal testosterone exposure decreases aldosterone production but maintains normal plasma volume and increases blood pressure in adult female rats. Biol. Reprod. 2016; 95: 1-11.

9. Gray A., Feldman H.A., McKinlay J.B. et al. Age, disease and changing sex hormones levels in middle-aged men: results of the Massachussets male aging study. J. Clin. Endocrinol. Metab. 1991; 73: 1016-1025. 
10. Kauffman J.M, Vermeulen A. Declining gonadal function in elderly men. Baillieres Clin. Endocrinol. Metab. 1997; 11: 289-309.

11. Khatibi A., Agardh C.D., Nyberg P. et al. Blood pressure in middle-aged women: are androgens involved? A population-based study of Swedish women: the Women's Health in the Lund Area study. J. Hypertens. 2007; 25: 2044-2050.

12. Tykarski A., Narkiewicz K., Gaciong Z. et al. 2015 Guidelines for the Management of Hypertension. Part 1-7. Arterial Hypertens. 2015; 2: 53-83.

13. Ziemens B., Wallaschofski H., Volzke H. et al. Positive association between testosterone, blood pressure, and hypertension in women: longitudinal findings from the Study of Health in Pomerania. J. Hypertens. 2013; 31: 1106-1113.

14. Khaw K.T., Barrett-Connor E. Blood pressure and endogenous testosterone in men: an inverse realtionship. J. Hypertens. 1988; 6: 329-332.

15. Dasinger J.H., Intapad S., Rudsenske B. et al. Chronic blockade of the androgen receptor abolishes age-dependent increases in blood pressure in female growth-restricted rats. Hypertension 2016; 67: $1281-1290$

16. Czekalski S., Ciechanowicz A. Mechanizmy i znaczenie sodowrażliwości ciśnienia tętniczego. Post. N. Med. 2004; 4: 4-11.

17. Hall J.E., Mizelle H.L., Hildebrandt D.A. et al. Abnormal pressure natriuresis. A cause or consequence of hypertension? Hypertension 1990; 15: 547-559.

18. Guyton A.C., Coleman T.G., Cowley A.V. Jr et al. Arterial pressure regulation. Overriding dominance of the kidneys in long-term regulation and in hypertension. Am. J. Med. 1972; 52: 584-594.

19. Zumoff B., Strain G.W., Miller L.K. et al. Plasma free and nonsex-hormone binding-globulin-bound testosterone are decreased in obese men in proportion to their of obesity. J. Endocrinol. Metab. 1990; 71: 929-931.

20. Haffner S.M., Karhapaa P., Mykkanen L. et al. Insulin resistance, body fat distribution and sex hormones in men. Diabetes 1994; 43: 212-219.

21. Endre T., Mattiason I., Berglund G. et al. Low testosterone and insulin resistance in hypertension prone men. J. Hum. Hypertens. 1996; 10: 755-761.

22. do Carmo J.M., da Silva A.A., Moak S.P. et al. Regulation of blood pressure, appetite, and glucose by CNS melanocortin system in hyperandrogenemic female SHR. Am. J. Hypertens. 2016; 29: 832-840.

23. Yu E.W., Lee H., Burnett-Bowie S.A.M. et al. Effects of androgens and estrogens on cardiometabolic parameters in young adult men. Abstracts of the Endocrine Society's 97th Annual Meeting and Expo, March 5-8, 2015 San Diego; doi:10.1210/endo- meetings.2015. RE.15.OR34-1.

24. Yassin A.A., Nettleship J., Almehmadi Y., Salman M., Saad F. Effects of continuous long-term testosterone therapy (TTh) on anthropometric, endocrine and metabolic parameters for up to 10 years in 115 hypogonadal elderly men: real-life experience from an observational registry study. Andrologia 2016; 48: 793-799.
25. Burl V.L., Whelton P., Roccella E.J. et al. Prevalence of hypertension in the US adult population results from the Third National Health and Nutrition Examination Survey 1988-1991. Hypertension 1995; 25: 305-313.

26. The Writing Group for the PEPI Trial. Effects of estrogen/progestin regiments on heart disease risk factors in postmenopausal women: the Postmenopausal Estrogen/Progestin (PEPI) Trial. JAMA 1995; 273: 199-208.

27. Akkad A.A., Halligan A.W., Abrams K. et al. Differing responses in blood pressure over 24 hours in normotensive women receiving oral or transdermal estrogen replacement therapy. Obstet. Gynecol. 1997; 89: 97-103.

28. Georgiopoulos G.A., Lambrinoudaki I., Athanasouli F. et al. Free androgen index as a predictor of blood pressure progression and accelerated vascular aging in menopause. Atherosclerosis 2016; 247: 177-183.

29. Soranno D., Prasad V., Oberfield D.R. et al. Hypertension and virilization caused by a unique dexoxycorticosterone and androgen-secreting adrenal adenoma. J. Pediatr. Endocrinol. Metab. 1999; 12: 215-220.

30. Talbott E., Guzick D., Clerici A. et al. Coronary heart disease risk factors in women with polycystic ovary syndrome. Arterioscler. Thromb. Vasc. Biol. 1995; 15: 821-826.

31. Mattson L.A.C.G., Hamberger L., Samsioe G. et al. Lipid metabolism in women with polycystic ovary syndrome: possible implications for an increased risk of coronary heart disease. Fertil. Steril. 1984; 42: $579-584$.

32. Patel S.M., Ratcliffe S.J., Reilly M.P. et al. Higher serum testosterone concentration in older women is associated with insulin resistance, metabolic syndrome, and cardiovascular disease. J. Clin. Endocrinol. Metab. 2009; 94: 4776-4784.

33. Olszanecka A., Kawecka-Jaszcz K., Czarnecka D. Association of free testosterone and sex hormone binding globulin with metabolic syndrome and subclinical atherosclerosis but not blood pressure in hypertensive perimenopausal women. Arch. Med. Sci. 2016; 12: 521-528.

34. Sullivan M.L., Martinez C.M., Gennis P. et al. The cardiac toxicity of anabolic steroids. Prog. Cardiovasc. Dis. 1998; 41: 1-15.

35. Marsh J.D., Lehmann M.H., Ritchie R.H. et al. Androgen receptors mediate hypertrophy in cardiac myocytes. Circulation 1998; 98: 256-261.

36. Vlachopoulos C., Pietri P., Ioakeimidis N. et al. Inverse association of total testosterone with central haemodynamics and left ventricular mass in hypertensive men. Atherosclerosis 2016; 250: 57-62.

37. Svartberg J., von Muhlen D., Schirmer H. et al. Association of endogenous testosterone with blood pressure and left ventricular mass in men. The Tromso Study. Eur. J. Endocrinol. 2004; 150: 65-71.

38. Gyllenborg J., Rasmussen S.L., Borch-Johnsen K. et al. Cardiovascular risk factors in men: the role of gonadal steroids and sex hormone-binding globulin. Metabolism 2001; 50: 882-888. 